\title{
Pemetaan Bahaya dan Kerentanan Bencana Kebakaran Hutan dan Lahan di Provinsi Riau
}

\author{
Sumardani Kusmajaya ${ }^{1}$, Supriyati ${ }^{1,2 *}$, Agung Adiputra ${ }^{1}$, dan M. Galih Permadi ${ }^{1}$ \\ ${ }^{1}$ Institut Pertanian Bogor, Jl. Raya Dramaga Bogor Jawa Barat 16680. \\ ${ }^{2}$ Badan Nasional Penanggulangan Bencana, Jl. Pramuka Kav. 38 Jakarta 13120.
}

*E-mail: supriyati.uppi@gmail.com

Received: 13112018 / Accepted: 11122018 / Published online: 17012019

\begin{abstract}
ABSTRAK
Provinsi Riau merupakan salah satu wilayah yang tidak pernah luput dari kebakaran hutan dan lahan. Salah satu penyebab kebakaran semakin parah, karena kejadian kebakaran hutan dan lahan terjadi pada ekosistem gambut. Di sisi lain, pemerintah daerah mempunyai kewajiban untuk menyusun, menetapkan, dan menginformasikan peta rawan bencana untuk melakukan perencanaan dan pemadaman dini, apabila terjadi kebakaran hutan dan lahan. Mengacu Perka BNPB Nomor 2 Tahun 2012, peta bahaya kebakaran hutan dan lahan Provinsi Riau dibuat menggunakan map algebra dan peta kerentanan dibuat secara dasimetrik. Hasil pemetaan menunjukkan daerah yang mempunyai bahaya tinggi adalah Kabupaten Indragiri Hilir dan Kabupaten Rokan Hilir, sedangkan kerentanan tertinggi berada di Kabupaten Kampar dan Kabupaten Indragiri Hilir.
\end{abstract}

Kata Kunci: Riau, Kebakaran, Gambut

\section{ABSTRACT}

Province of Riau is one of the regions that is always threatened by forest and land fires. One of the causes that makes the fires become worse is that the fires occur in peat ecosystem. Therefore, the local government is under an obligation to compile, determine and inform the disaster risk map to conduct the planning as well as the early fire outage when forest and land fires occur. Referring to Perka BNPB No.2, 2012, disaster risk map is made using algebra map and vulnerability map is made dasymetrically. The result of mapping shows the high risk regions are Kabupaten Indragiri Hilir and Kabupaten Rokan Hilir, meanwhile, the highest vulnerability is in Kabupaten Kampar and Kabupaten Indragiri Hilir.

Keywords: Riau, Fires, Peat

\section{PENDAHULUAN}

Provinsi Riau merupakan salah satu wilayah yang tidak pernah luput dari kebakaran hutan dan lahan pada saat musim kemarau. Salah satu penyebab kebakaran semakin parah, karena kejadian kebakaran hutan dan lahan terjadi pada ekosistem gambut. Ketika pembersihan kawasan hutan skala lanskap dan drainase gambut dikombinasikan dengan penggunaan api yang meluas, akibat yang tidak dapat dihindari adalah peningkatan kebakaran yang tak terkendali (Page, 2016). Pengeringan dan konversi lahan 
Jurnal Geografi, Edukasi dan Lingkungan (JGEL) Vol. 3, No. 1, Januari 2019:55-61

P-ISSN: 2579-8499; E-ISSN: 2579-8510

DOI: https://doi.org/10.29405/jgel.v3i1.2993

Website: http://journal.uhamka.ac.id/index.php/jgel

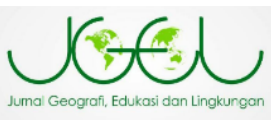

gambut, yang terutama didorong oleh produksi minyak kelapa sawit, berkontribusi terhadap peningkatan intensitas kabut asap dari kebakaran (Glauber dkk., 2016). Pemerintah Provinsi Riau menyatakan telah melakukan pengendalian terhadap kebakaran hutan dan lahan yang menyebabkan kabut asap semakin tebal dan mengganggu mobilitas masyarakat, namun kebakaran dan kabut asap tetap muncul kembali (Meiwanda, 2016).

Peningkatan konsentrasi CO2 mengakibatkan suhu permukaan bumi meningkat. Peningkatan suhu tersebut mengakibatkan fenomena El-Nino Southern Oscilation (ENSO), di kawasan Asia Tenggara lebih sering terjadi dan berdampak pada peningkatan intensitas kejadian curah hujan yang ekstrem. Perubahan iklim global yang menyebabkan kekeringan berkepanjangan di Indonesia itulah yang menjadi salah satu faktor pemicu kebakaran lahan dan hutan (Amri dkk., 2016).

Data yang dikeluarkan oleh Polda Riau memperlihatkan jumlah kasus kebakaran hutan dan lahan yang terjadi pada tahun 2014-2015 dimana areal yang terbakar merupakan lahan masyarakat, perusahaan dan areal konsesi milik perusahaan swasta (Meiwanda, 2016). Hal ini menandakan bahwa manusia merupakan salah satu faktor kerentanan yang menyebabkan kebakaran hutan dan lahan.

Di sisi lain, pemerintah daerah mempunyai tugas menyusun, menetapkan, dan menginformasikan peta rawan bencana (UU No. 24, 2007). Peta rawan bencana tersebut digunakan untuk membuat perencanaan dalam upaya penanggulangan kebakaran hutan dan lahan meliputi pencegahan dan pemadaman dini. Informasi mengenai daerah rawan kebakaran merupakan informasi yang sangat penting dan diperlukan oleh pengambil keputusan di dalam kegiatan pengendalian kebakaran hutan dan lahan. Peta daerah rawan kebakaran karenanya berperan penting di dalam membantu mengambil keputusan tersebut. Penyajian secara spasial akan lebih membantu memberikan gambaran yang jelas dan akurat mengenai lokasi, jarak serta aksesibilitas antara lokasi daerah rawan dengan sumber daya pemadaman yang ada di lapangan (Solichin dkk., 2007).

\section{METODE PENELITIAN \\ Waktu dan Lokasi Penelitian}

Pemetaan bahaya dan kerentanan bencana kebakaran hutan dan lahan di lakukan di wilayah Provinsi Riau yang terdiri dari 12 kabupaten (Gambar 1). Secara astronomis terletak antara $01^{\circ} 05^{\prime}$ 00' Lintang Selatan sampai $02^{\circ} 25^{\prime}$ 00", Lintang Utara dan antara $100^{\circ} 00^{\prime}$ 00'sampai $105^{\circ}$ 05' 00" Bujur Timur. Penelitian ini dilakukan pada Januari 2017.

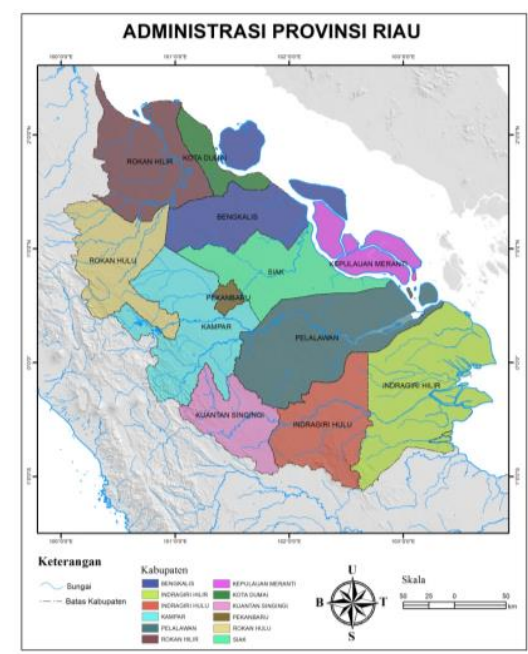

Gambar 1: Peta Administrasi Provinsi Riau

\section{Alat dan Bahan}

Dalam penelitian ini alat pengolah data yang digunakan adalah komputer dengan piranti lunak sistem informasi geografis (ArcGIS 10.2), dan Microsoft Office untuk penulisan hasil. Data yang 
Jurnal Geografi, Edukasi dan Lingkungan (JGEL) Vol. 3, No. 1, Januari 2019:55-61

P-ISSN: 2579-8499; E-ISSN: 2579-8510

DOI: https://doi.org/10.29405/jgel.v3i1.2993

Website: http://journal.uhamka.ac.id/index.php/jgel

digunakan adalah data sekunder, yang berupa data kewilayahan yang dirinci pada Tabel 1.

Tabel 1. Jenis dan Sumber Data yang Digunakan

\begin{tabular}{clcc}
\hline NO & Jenis Data & Sumber & Tahun \\
\hline $\mathbf{1}$ & Administrasi & BIG & 2014 \\
\hline $\mathbf{2}$ & Jenis tanah & BBSDLP & 2014 \\
\hline $\mathbf{3}$ & Tutupan lahan & KLHK & 2014 \\
\hline $\mathbf{4}$ & Curah hujan & BMKG & 2014 \\
\hline
\end{tabular}

\section{Jenis Penelitian}

Jenis penelitian yang dilakukan merupakan penelitian kuantitatif. Metode kuantitatif digunakan karena berdasarkan analisis pemberian skor dan bobot pada setiap parameter analisis.

Metode pengumpulan, pengolahan, dan Analisis Data

Penelitian ini menggunakan unit analisis wilayah. Objek kajian dalam penelitian ini adalah daerah rawan bahaya kebakaran hutan dan lahan di Provinsi Riau. Analisis daerah bahaya kebakaran hutan dan lahan digunakan tools Raster Calculator/Map Algebra, yang merupakan bagian dari ArcToolbox di dalam modul spatial analyst. Map algebra adalah tool yang dapat digunakan untuk menjalankan semua tool analisis spasial, operator, dan fungsi untuk analisis geografis serta digunakan hanya untuk analisis spasial data raster.

Kerentanan sosial dihitung dengan menggunakan pendekatan dasimetrik. Pendekatan dasimetrik adalah sebuah pendekatan dimana setiap piksel merepresentasikan nilai parameter sosial (jumlah jiwa) di seluruh wilayah pemukiman. Pendistribusian nilai parameter sosial dapat dilakukan dengan menggunakan persamaan berikut (Khomarudin dkk., 2010):

$$
\begin{aligned}
& X_{d}=\sum_{i=1}^{n} P_{i} \\
& P_{j}=\sum_{i=1}^{n} P_{i j} \\
& P_{i j}=\frac{S_{i j}}{\sum_{i, j=1}^{k} s_{i j}} x X_{d}
\end{aligned}
$$

Keterangan:

$\mathrm{X}_{\mathrm{d}}=$ jumlah populasi di dalam unit administrasi

$\mathrm{P}_{\mathrm{i}}=$ jumlah populasi di dalam pemukiman ke-i

$P i j=$ jumlah populasi di polygon ke-j di dalam pemukiman ke-i;

$\mathrm{Sij}=$ poligon ke-j di dalam pemukiman ke-i di dalam unit administrasi;

$\mathrm{n}=$ jumlah poligon di dalam pemukiman di dalam unit administrasi

Masing-masing parameter dianalisis dengan menggunakan metode skoring sesuai Perka BNPB No. 2 Tahun 2012 untuk memperoleh nilai skor kerentanan sosial pada Tabel 2. 
Jurnal Geografi, Edukasi dan Lingkungan (JGEL) Vol. 3, No. 1, Januari 2019:55-61

P-ISSN: 2579-8499; E-ISSN: 2579-8510

DOI: https://doi.org/10.29405/jgel.v3i1.2993

Website: http://journal.uhamka.ac.id/index.php/jgel

Tabel 2. Skoring dan pembobotan bahaya kebakaran hutan dan lahan

\begin{tabular}{cllll}
\hline Parameter & \multicolumn{3}{c}{ Skor } & \multirow{2}{*}{ Bobot } \\
\cline { 2 - 4 } & hutan & 0,333 & 0,666 & 1 \\
\hline Jenis lahan & kebun/ & tegalan/ ladang, \\
perkebunan & & $\begin{array}{l}\text { semak belukar, } \\
\text { padang rumput } \\
\text { kering }\end{array}$ & \\
\hline $\begin{array}{c}\text { Iklim dan curah } \\
\text { hujan }\end{array}$ & $>3000 \mathrm{~mm}$ & $1500-3000 \mathrm{~mm}$ & $<1500 \mathrm{~mm}$ & $40 \%$ \\
\hline Jenis tanah & non organik / mineral & - & organik / Gambut & $20 \%$ \\
\hline
\end{tabular}

Sumber: BNPB 2012

\section{HASIL DAN PEMBAHASAN \\ Curah Hujan}

Provinsi Riau memiliki luas area sebesar 8.915.016 hektar, membentang dari lereng Bukit Barisan sampai dengan Selat Malaka. Di daerah daratan terdapat 15 sungai, diantaranya ada 4 sungai yang mempunyai arti penting sebagai prasarana perhubungan (BPS Riau, 2016).

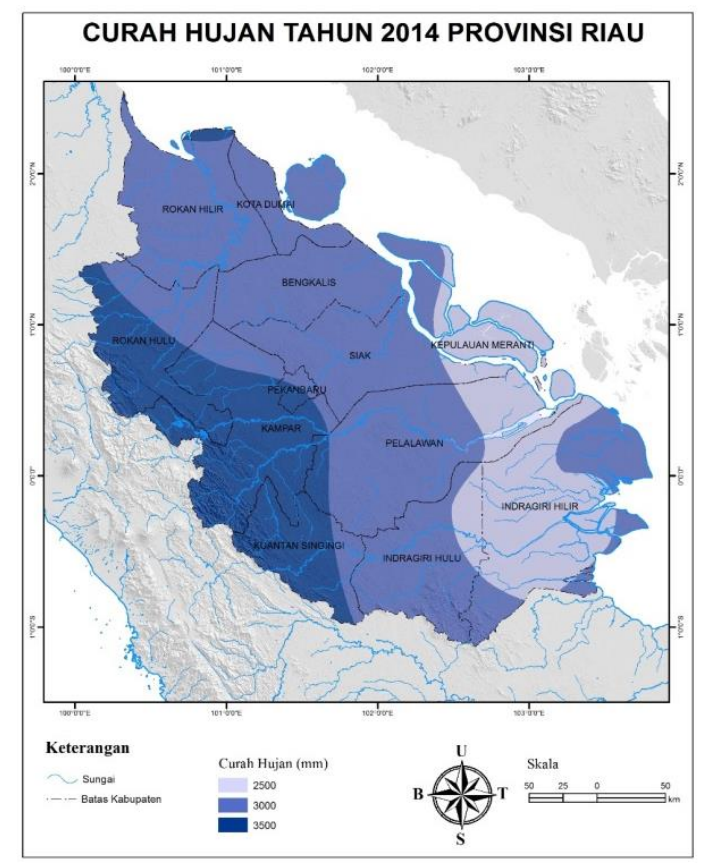

Gambar 2: Peta Curah Hujan Provinsi Riau Tahun 2014

Daerah Riau beriklim tropis basah dengan rata-rata curah hujan berkisar antara $1.700-4.000 \mathrm{~mm}$ per tahun yang dipengaruhi oleh musim kemarau dan musim hujan. Suhu udara rata-rata di

Kota Pekanbaru tahun 2012 menunjukkan $26,0^{\circ} \mathrm{C}$ dengan suhu maksimum $35,1^{\circ} \mathrm{C}$ dan suhu minimum $21,8^{\circ} \mathrm{C}$ (BPS Riau, 2015).

Peta curah hujan Provinsi Riau tahun 2014 dari Badan Meteorologi Klimatologi dan Geofisika (BMKG) disajikan pada Gambar 2.

\section{Tutupan Lahan}

Penutup lahan menggambarkan material-material yang tampak pada permukaan bumi, sedangkan penggunaan lahan lebih berkaitan dengan aktivitas manusia di tempat tersebut. Tutupan lahan di Provinsi Riau ditunjukkan pada Tabel 3.

Tabel 3. Tutupan Lahan Provinsi Riau

\begin{tabular}{clrc}
\hline NO & \multicolumn{1}{c}{ Kelas } & Luas $(\mathbf{H a})$ & \% \\
\hline $\mathbf{1}$ & $\begin{array}{l}\text { Bandara/ } \\
\text { Pelabuhan }\end{array}$ & 859,54 & 0,01 \\
\hline $\mathbf{2}$ & $\begin{array}{l}\text { Hutan lahan } \\
\text { kering primer }\end{array}$ & $161.969,32$ & 1,80 \\
\hline $\mathbf{3}$ & $\begin{array}{l}\text { Hutan lahan } \\
\text { kering sekunder }\end{array}$ & $360.134,91$ & 4,00 \\
\hline $\mathbf{4}$ & $\begin{array}{l}\text { Hutan mangrove } \\
\text { primer }\end{array}$ & $5.288,67$ & 0,06 \\
\hline $\mathbf{5}$ & $\begin{array}{l}\text { Hutan mangrove } \\
\text { sekunder }\end{array}$ & $160.819,72$ & 1,79 \\
\hline $\mathbf{6}$ & $\begin{array}{l}\text { Hutan rawa } \\
\text { primer }\end{array}$ & $70.101,64$ & 0,78 \\
\hline $\mathbf{7}$ & $\begin{array}{l}\text { Hutan rawa } \\
\text { sekunder }\end{array}$ & $1.024 .009,96$ & 11,37 \\
$\mathbf{8}$ & Hutan Tanaman & $885.725,85$ & 9,84 \\
\hline
\end{tabular}


Jurnal Geografi, Edukasi dan Lingkungan (JGEL) Vol. 3, No. 1, Januari 2019:55-61

P-ISSN: 2579-8499; E-ISSN: 2579-8510

DOI: https://doi.org/10.29405/jgel.v3i1.2993

Website: http://journal.uhamka.ac.id/index.php/jgel

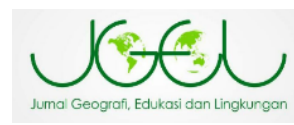

\begin{tabular}{clrc}
\hline & Industri (HTI) & & \\
\hline $\mathbf{9}$ & Perkebunan & $2.514 .544,93$ & 27,93 \\
\hline $\mathbf{1 0}$ & Permukiman & $116.369,30$ & 1,29 \\
\hline $\mathbf{1 1}$ & Pertambangan & $34.587,67$ & 0,38 \\
\hline $\mathbf{1 2}$ & $\begin{array}{l}\text { Pertanian lahan } \\
\text { kering }\end{array}$ & $362.093,85$ & 4,02 \\
\hline $\mathbf{1 3}$ & $\begin{array}{l}\text { Pertanian lahan } \\
\text { kering bercampur } \\
\text { dengan semak }\end{array}$ & $1.539 .574,17$ & 17,10 \\
\hline $\mathbf{1 4}$ & Rawa & $26.826,63$ & 0,30 \\
\hline $\mathbf{1 5}$ & Savana & 387,41 & 0,00 \\
\hline $\mathbf{1 6}$ & Sawah & $193.508,91$ & 2,15 \\
\hline $\mathbf{1 7}$ & Semak/belukar & $19.267,42$ & 0,21 \\
\hline $\mathbf{1 8}$ & Semak/belukar & $1.030 .924,95$ & 11,45 \\
& rawa & $2.783,43$ & 0,03 \\
\hline $\mathbf{1 9}$ & Tambak & $382.323,85$ & 4,25 \\
\hline $\mathbf{2 0}$ & Tanah terbuka & $2.888,55$ & 0,03 \\
\hline $\mathbf{2 1}$ & Transmigrasi & $109.214,65$ & 1,21 \\
\hline $\mathbf{2 2}$ & Tubuh air & $9.004 .205,34$ & 1,00 \\
\hline & Jumlah & & \\
\hline
\end{tabular}

Sumber: KLHK 2014.

Tutupan lahan Provinsi Riau tahun 2014 dari Kementerian Lingkungan Hidup dan Kehutanan disajikan dalam Tabel 3 dan dipetakan dalam Gambar 3.

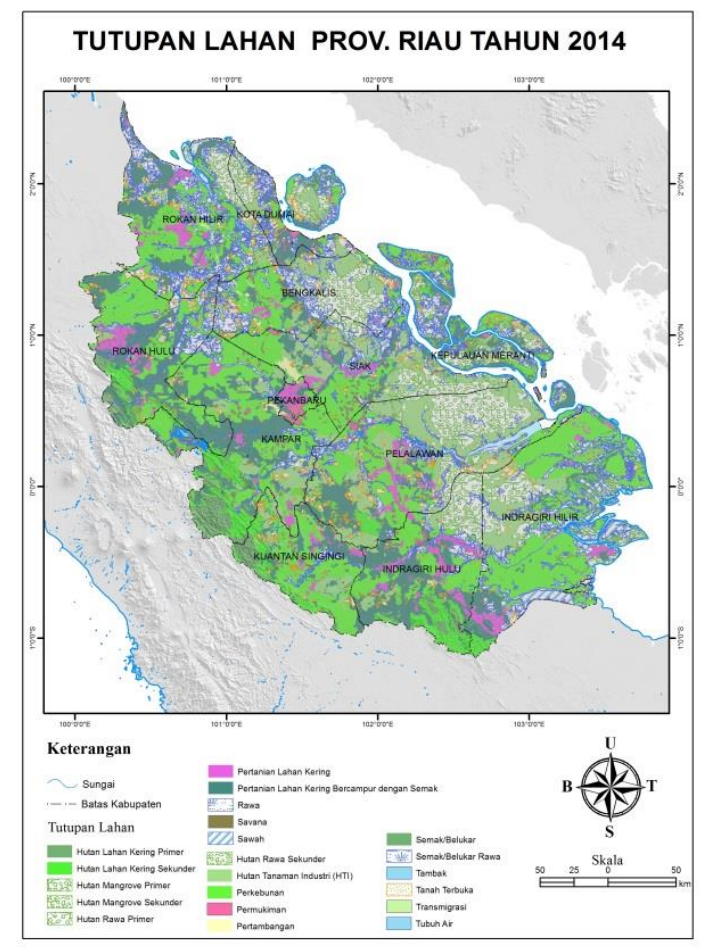

Gambar 3: Tutupan Lahan Provinsi Riau

\section{Jenis Tanah}

Dari luas daerah Provinsi Riau seluas 8,9 juta Ha sebagian besar jenis tanahnya adalah histosols organik yaitu 3,8 juta Ha lebih atau 43,35\%, diikuti oleh jenis tanah ultisols seluas 2,6 juta $\mathrm{Ha}$ lebih atau 29,51\% (BPS Riau, 2015).

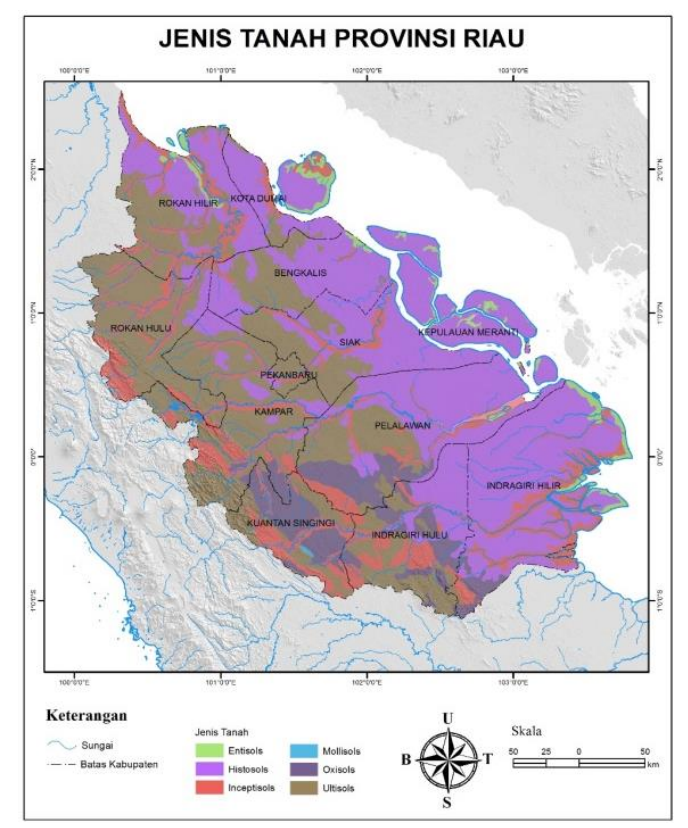

Gambar 4: Jenis Tanah di Provinsi Riau

\section{Bahaya Bencana Kebakaran}

Bahaya kebakaran hutan dan lahan dan hutan dibuat sesuai metode yang ada di dalam Perka BNPB No. 2 Tahun 2012. Parameter penyusun bahaya kebakaran hutan dan lahan terdiri dari parameter jenis hutan dan lahan, iklim, dan jenis tanah. Setiap parameter diidentifikasi untuk mendapatkan kelas parameter dan dinilai berdasarkan tingkat pengaruh/ kepentingan masing-masing kelas menggunakan metode skoring. Tools yang digunakan dalam menganalis adalah raster calculator sehingga persentasi masing-masing parameter disajikan pada Persamaan 4:

$(40 \% *$ Curah hujan $)+(40 \% *$ iklim $)+$ (20\%*Jenis Tanah) 
Jurnal Geografi, Edukasi dan Lingkungan (JGEL) Vol. 3, No. 1, Januari 2019:55-61

P-ISSN: 2579-8499; E-ISSN: 2579-8510

DOI: https://doi.org/10.29405/jgel.v3i1.2993

Website: http://journal.uhamka.ac.id/index.php/jgel

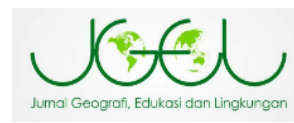

Hasil perhitungan dari Persamaan 4 dibagi menjadi 3 kelas, yaitu kelas 1 , kelas 2, dan kelas 3. Hasil analisis bahaya kebakaran disajikan pada Tabel 4.

Tabel 4. Bahaya Kebakaran per Kabupaten di Provinsi Riau

\begin{tabular}{llrrr}
\hline \multirow{2}{*}{ No } & Kabupaten & \multicolumn{3}{c}{ Luas (Ha) } \\
\cline { 3 - 5 } & & Kelas 1 & Kelas 2 & Kelas 3 \\
\hline 1 & Bengkalis & 157391 & 423706 & 206877 \\
\hline 2 & Indragiri & 247381 & 465819 & 594250 \\
& Hilir & & & \\
\hline 3 & Indragiri & 55818 & 366716 & 313619 \\
& Hulu & & & \\
\hline 4 & Kampar & 286596 & 647555 & 66790 \\
\hline 5 & Kepulauan & 141119 & 137958 & 56483 \\
& Meranti & & & \\
\hline 6 & Kota Dumai & 70957 & 81583 & 40616 \\
\hline 7 & Kuantan & 128284 & 327224 & 40768 \\
& Singingi & & & \\
\hline 8 & Pekanbaru & 0 & 23217 & 19711 \\
\hline 9 & Pelalawan & 112734 & 810514 & 258622 \\
\hline 10 & Rokan Hilir & 185108 & 295088 & 340073 \\
\hline 11 & Rokan Hulu & 110288 & 530558 & 100351 \\
\hline 12 & Siak & 107777 & 446938 & 129862 \\
\hline
\end{tabular}

Dari Tabel 4 dapat diketahui luas lahan tertinggi yang masuk dalam kelas 3 adalah Kabupaten Indragiri Hilir dengan luas 594.249,48 ha (7\%), juga kabupaten Rokan Hilir dengan luas 340.073,19 ha $(4,08 \%)$. Peta bahaya kebakaran hutan dapat dilihat pada Gambar 5.

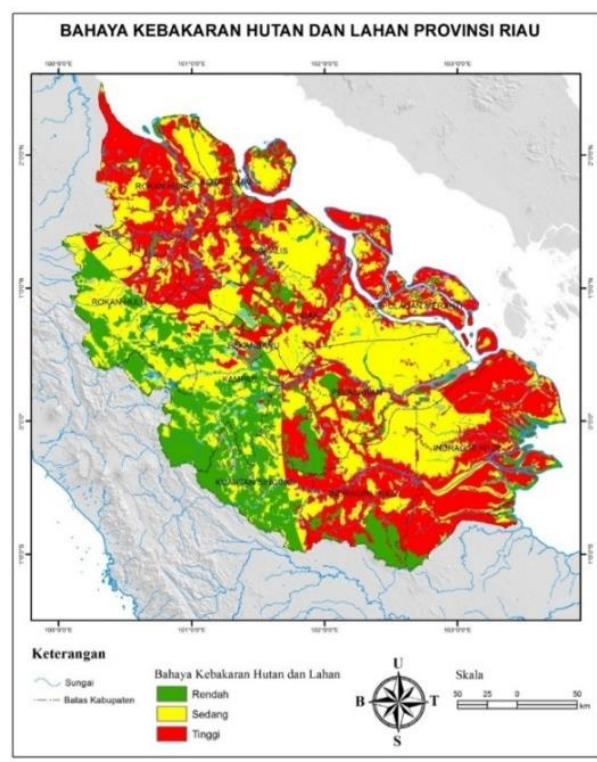

Gambar 5: Bahaya Kebakaran Hutan dan Lahan di Provinsi Riau

\section{Kerentanan Bencana Kebakaran}

Kerentanan penduduk dianalisis berdasarkan distribusi penduduk yang mengacu dari ketentuan BNPB dan dikembangkan oleh penulis. Data yang dibutuhkan dalam menyusun kerentanan adalah data BPS yang terkait jumlah penduduk per kabupaten di Provinsi Riau, yang kemudian didistribusikan merata ke unit piksel pemukiman di tiap kabupaten/ kota. Hasil dari distribusi penduduk kemudian ditumpangsusunkan dengan peta bahaya kebakaran hutan dan lahan, sehingga dari data ini diperoleh jumlah penduduk yang berpotensi terdampak.

Berdasarkan hasil penelitian apabila dilihat secara luas, maka diperoleh Kabupaten Kampar yang mempunyai kerentanan tertingggi, dan Kepulauan Meranti yang terendah. Namun secara persentasi total jumlah penduduk per kabupaten maka di peroleh Kabupaten Indragiri Hilir yang memiliki potensi tertinggi dan Kabupaten Pekanbaru terendah. 
Jurnal Geografi, Edukasi dan Lingkungan (JGEL) Vol. 3, No. 1, Januari 2019:55-61

P-ISSN: 2579-8499; E-ISSN: 2579-8510

DOI: https://doi.org/10.29405/jgel.v3i1.2993

Website: http://journal.uhamka.ac.id/index.php/jgel

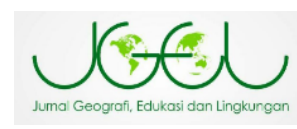

KESIMPULAN.

Berdasarkan analisis bahaya kebakaran hutan dan lahan di Provinsi Riau, luas lahan tertinggi yang masuk dalam bahaya kelas tinggi adalah Kabupaten Indragiri Hilir dengan luas 594.249,48 ha (7\%), dan kabupaten Rokan Hilir dengan luas 340.073,19 ha $(4,08 \%)$.

Ditinjau dari segi kerentanan, Kabupaten Kampar yang mempunyai kerentanan tertingggi, dan Kepulauan Meranti yang terendah. Hal ini di dasarkan atas kemungkinan masyarakat yang terdampak, Kabupaten Indragiri Hilir yang memiliki potensi tertinggi dan Kabupaten Pekanbaru terendah.

\section{DAFTAR PUSTAKA}

Anonim, 2015, Riau dalam Angka Tahun 2015, Pekanbaru: BPS Provinsi Riau.

Anonim, 2016, Provinsi Riau dalam Angka Tahun 2016, Pekanbaru: BPS Provinsi Riau.

Amri, M.R., Yulianti, G., Yunus, R., Wiguna S., Adi, A.W., Ichwana, A.N., Randongkir, R.E., Septian, R.T., 2016, Risiko Bencana Indonesia, Jakarta: BNPB.

Glauber, A.J., Moyer, S., Adriani, M., Gunawan, I., 2016, Kerugian dari Kebakaran Hutan- Analisa Dampak Ekonomi dari Krisis Kebakaran tahun 2015, Jakarta: World Bank Group.

Khomarudin, M.R., Strunz, G., Ludwig, R., Zoßeder, K., 2010, Hazard analysis and estimation of people exposure as contribution to tsunami risk assessment in the West Coast of
Sumatra, Zeitschrift für Geomorphologie 54(3): 337-356.

Meiwanda, G. (2016). Kapabilitas Pemerintah Daerah Provinsi Riau: Hambatan dan Tantangan Pengendalian Kebakaran Hutan dan Lahan. Jurnal Ilmu Sosial dan Ilmu Politik 19 (3): 251-263.

Page, S., 2016, Memahami Dinamika Kebakaran Lahan Gambut di Indonesia. Jurnal Lestari 1(1): 413.

Peraturan Republik Indonesia, UndangUndang Nomor 24 Tahun 2007 tentang Penanggulangan Bencana.

Peraturan Republik Indonesia, Peraturan Kepala Badan Nasional Penanggulangan Bencana Nomor 2 Tahun 2012 tentang Pedoman Pengkajian Risiko Bencana.

Solichin, Tarigan, L., Kimman, P., Firman, B., Bagyono, R., 2007, Sistem Informasi Kebakaran: Pemetaan Daerah Kebakaran, Palembang: South Sumatra Forest Fire Management Project. 